\title{
PENDAMPINGAN PEMBUATAN MEDIA PEMBELAJARAN BERBENTUK FLASH-LIKE POWERPOINT BAGI GURU IPA SMP DI KABUPATEN JOMBANG
}

\author{
Oleh: \\ Martini', Ahmad Qosyim², Aris Rudi Purnomo \\ 1,2,3Jurusan IPA, FMIPA Universitas Negeri Surabaya \\ 1martini@unesa.ac.id
}

\begin{abstract}
Abstrak
Di era digital, penguasaan terhadap teknologi komputer mutlak dimiliki oleh siapapun, tidak terkecuali bagi seorang guru. Guru harus mampu memanfaatkan teknologi sebagai media pembelajaran kepada siswa-siswanya. Hal ini berguna untuk meningkatkan motivasi siswa saat mengikuti pembelajaran. Media pembelajaran juga dapat digunakan untuk menggambarkan fenomena alam yang prosesnya berlangsung secara abstrak. Kegiatan pendampingan pembuatan media flash-like powerpoint untuk menambah pengetahuan dan keterampilan guruguru dalam mengembangkan media pembelajaran. Pendampingan dilaksanakan di Kabupaten Jombang dan diikuti oleh 20 (dua puluh) guru IPA dari SMP Negeri se-kabupaten Jombang. Metode pelaksanaan terdiri atas tahap perencanaan, implementasi, dan evaluasi. Hasil dari kegiatan ini berupa media flash-like powerpoint karya guru-guru IPA. Respon peserta terhadap kegiatan pendampingan adalah positif. Peserta merasa mendapat manfaat dari kegiatan ini. Peserta juga merasa lebih termotivasi untuk mengajar, dan utamanya peserta juga mendapatkan keterampilan (life skill) untuk mengembangkan media-media pembelajaran lebih lanjut.
\end{abstract}

Kata Kunci: teknologi, media pembelajaran, flash-like powerpoint, materi IPA

\begin{abstract}
In the digital era, mastery of technology and computer is an compulsory skill for everyone, including for a teacher. The teacher must be capable to use technology as learning media. This is to motivate the students in the class. Learning media also can be used to show natural phenomena that the process seems abstract to students. The tuition of making flash-like powerpoint media is useful to increase teachers' knowledge and skill in developing learning media. This tuition was held in Jombang Regency and attended by 20 (twenty) science teacher of public yunior high school of Jombang Regency. The method of tuition consisted of three steps, i.e. planning, implementing, and evaluating. The result of the tuition is flash-like powerpoint media made by science teachers. The participants of this tuition gave positive respond. They also got many benefit from this tuition. They were motivated to teaching and especially they also got some life skills to develop learning media.
\end{abstract}

Keywords: technology, learning media, flash-like powerpoint, IPA matter

\section{PENDAHULUAN}

Perkembangan teknologi seharusnya telah menyentuh level pengajaran di sekolah lanjutan. Namun faktanya, ICT (Information, Communication, and Technology) sebagai penunjang sarana pembelajaran belum dimanfaatkan dengan baik. Ini disebabkan oleh dua faktor, yaitu sarana sekolah dan sumber daya manusia (SDM) yang mengelolanya. Sarana sekolah dapat berupa ketersediaan perangkat komputer dan jaringan internet, sedangkan faktor SDM mencakup keahlian manusia untuk menggunakan teknologi guna maksud dan tujuan tertentu.

Pemanfaatan teknologi pada pembelajaran erat kaitannya dengan pengembangan media pembelajaran. Media pembelajaran didefinisikan sebagai 
seperangkat alat yang digunakan untuk membawa informasi dari guru kepada siswasiswanya. Menurut Kozma (1991), pembelajaran dengan media menyangkut tiga aspek yaitu aspek teknologi, aspek simbol yang digunakan, dan aspek kemampuan prosesnya.

Berkaitan dengan media pembelajaran yang menggunakan komputer, ketiga aspek yang disebutkan di atas memiliki nilai tersendiri. Dari aspek teknologi, media ini dipandang sebagai suatu bentuk modernisasi yang memanfaatkan kecanggihan perangkat komputer. Aspek simbol memfokuskan pada kemampuan media untuk menampilkan pesan-pesan dalam bentuk gambar, gerak, dan suara. Media dengan komputerisasi modern mampu menggabungkan ketiga simbol menjadi satu sehingga kompleksitasnya tinggi. Untuk siswa-siswa yang memiliki kemampuan belajar auditori dan visual, pengalaman ini memberikan efek yang baik untuk belajar. Dari sudut pandang kemampuan pemrosesan, media pembelajaran dengan kemampuan komputer, jika diterapkan pada bidang IPA, maka akan mampu memvisualisasikan fenomenafenomena alam seperti gunung meletus, gempa bumi, dan reproduksi yang lebih baik karena dapat memodelkan setiap prosesproses yang terjadi. Ini membuat media pembelajaran berbasis komputer menjadi lebih unggul dibandingkan dengan media pembelajaran yang lain sesuai karakteristik tiga aspek tersebut.

Untuk membuat media pembelajaran berbasis komputer yang baik, dalam hal ini adalah media dengan software PowerPoint, guru perlu memperhatikan beberapa indikator seperti yang diungkapkan oleh Colemen (2009). Pertama, desain template yang digunakan harus sesuai dengan tema atau topik pembelajaran. Kedua, huruf yang digunakan memiliki ukuran yang proporsional dengan jarak pandang siswa sehingga dapat terlihat dengan jelas. Ketiga, kombinasi teks, gambar, video, dan suara perlu memperhatikan ketelitian agar tidak menimbulkan pemahaman ganda pada siswa.

Di kalangan guru IPA SMP, penggunaan media pembelajaran dengan PowerPoint belum secara maksimal digunakan dengan baik. Sebagai contoh, di Kecamatan Kudu, Kabupaten Jombang, umumnya guru belum terampil atau bahkan belum pernah memanfaatkan keunggulan-keunggulan yang dimiliki oleh PowerPoint. Pada wawancara yang telah dilakukan, untuk mengajar materi tentang reproduksi, siswa mengalami kesulitan untuk mendeskripsikan reproduksi hewan secara ovovivipar. Guru, dalam hal ini, tidak menjelaskan dengan video animasi yang didukung dengan poin-poin penjelasan yang baik. Media papan tulis lazim digunakan untuk menjelaskan jenis reproduksi tersebut sehingga siswa-siswa SMPyang mengalami pembelajaran tipe tersebut (pembelajaran tradisional) mengalami kebosanan untuk belajar. Untuk itu, PowerPoint perlu diperkenalkan lebih jauh kepada guru-guru tersebut melalui kegiatan pengabdian pada masyarakat ini.Menurut Drouin, Hile, Vartanian, dan Webb (2013) penggunaan teknologi tersebut akan memacu minat siswa belajar karena dapat menjelaskan materi secara lebih jelas dan sesuai perkembangan anak yang berada pada era digital.

Berbeda dengan penggunaan media PowerPoint selama ini yang cenderung hanya menampilkan efek visual yang standar, kegiatan yang berbentuk pelatihan ini akan mengajarkan beberapa efek pada PowerPoint yang sebenarnya sudah ada seperti yang ditunjukkan oleh media pembelajaran berbentuk flashsehingga disebut dengan flash-like PowerPoint. Efek yang diajarkan meliputi timing animation dan tipografi kinetik yang dapat membantu menjelaskan proses gerak (Harrington dan Rekdal, 2007) seperti yang sering muncul pada materi IPA. Keunggulan lainnya ialah software PowerPoint tidak memerlukan spesifikasi komputer yang tinggi sehingga dengan komputer yang ada di sekolah, guru-guru akan mampu membuat presentasi layaknya flash. Lainnya, guru dapat secara lebih mudah mengoperasikan karena beberapa fitur sudah dikenal.

Dari kegiatan yang akan dilaksanakan ini, program pengabdian pada masyarakat ini berharap akan ada peningkatan kompetensi guru menyangkut pembuatan media pembelajaran dengan kualitas yang baik, yaitu terbaca, mudah dipahami, dan menarik bagi siswa.

\section{METODE PELAKSANAAN}

Kegiatan ini bertujuan memberikan pendampingan pembuatan media pembelajaran berbentuk flash-like powerpoint kepada guru-guru IPA se-kabupaten Jombang.

Kegiatan pendampingan terdiri dari tiga tahapan, yaitu: perencanaan, implementasi, 
dan evaluasi. Pada tahap perencanaan dilakukan analisis teori dan ide berdasarkan penelitian dan kenyataan di lapangan: Hal-hal apa saja yang dapat digunakan guru untuk meningkatkan kualitas pembelajarannya di kelas?.

Pada tahap implementasi, dilaksanakan worshop pendampingan pembuatan media pembelajaran flash-like powerpoint dengan diawali pemberian informasi terkait PowerPoint, Videoscribe, iSpring Suite, dan Teknik pembuatan media flash-like PowerPoint.

Pada tahap akhir, yaitu evaluasi, dilakukan pemantauan dan evaluasi hasil praktik yang merupakan kegiatan setelah pendampingan dan Analisis-sintesis hasil praktik pembuatan media flask-like PowerPoint.

Dalam kegiatan ini dilibatkan 20 (dua puluh) guru IPA dari SMP Negeri sekabupaten Jombang.

Data yang dikumpulkan berupa produk media pembelajaran yang dinilai berdasarkan organisasi, isi, grafis, dan animasi, dengan skor 4 (sangat baik), 3 (baik), 2 (cukup) dan 1 (kurang). Selain itu juga dikumpulkan data respon untuk mengetahui respon peserta terhadap kegiatan pendampingan yang diberikan. kegiatan dikatakan berhasil jika peserta memberikan respon positif dengan persentase $>80 \%$.

\section{HASIL DAN PEMBAHASAN}

Pada tahap perencanaan, sebelum kegiatan pendampingan, tim PKM menyiapkan materi workshop. Materi meliputi PowerPoint, Videoscribe, iSpring Suite, dan teknik pembuatan flash-like powerpoint.

Untuk powerpoint, ini bukan sesuatu yang asing untuk para guru, karena umumnya mereka sudah menggunakan software ini.
Terkait videoscribe, ini merupakan perangkat lunak yang digunakan untuk presentasi, seperti halnya PowerPoint. Meskipun samasama menggunakan layer sebagai tempat mengatur konten berupa teks dan gambar, basis format tampilannya sangat berbeda. Videoscribe menampilkan presentasi berupa video animasi. Hasilnya dapat diekspor untuk ditampilkan dalam format .mp4 dan .pptx jika dimasukkan ke dalam PowerPoint.

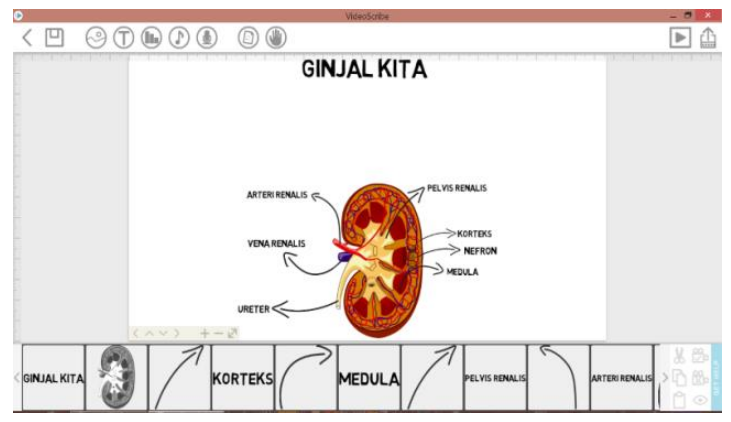

Gambar 1. Tampilan videoscribe

iSpring Suite merupakan bagian pada pembuatan media pembelajaran berbasis flash-like PowerPoint. Software iSpring suite versi 8 menawarkan mode penyimpanan file PowerPoint dalam bentuk executable (.exe), html5, dan flash (.swf). Dengan memanfaatkan fitur tersebut, flash-like PowerPoint file dapat disimpan ke dalam file berekstensi .swf.

Pada tahap implementasi, workshop pendampingan pembuatan media flash-lika powerpoint, membagi peserta ke dalam 4 (empat) kelompok. Setiap kelompok dapat memilih topik untuk media yang akan dibuat. Empat topik yang terpilih, adalah sebagai berikut.

Tabel 1. Topik media

\begin{tabular}{cc}
\hline Kel & Topik \\
\hline 1 & Tuas \\
\hline 2 & Sistem Pencernaan \\
\hline 3 & Sistem Pernapasan \\
\hline 4 & Zat Adiktif \\
\hline
\end{tabular}

Setelah penetapan topik, peserta mulai membuat media seperti yang dilatihkan. Hasil pendampingan, dari empat kelompok yang terbentuk, ada 2 kelompok yang dapat mempresentasikan hasil media flash-like PowerPoint, 1 kelompok hanya PowerPoint, dan 1 kelompok tidak mempresentasikan karena berhalangan hadir. Hasil media flashlike PowerPoint, salah satu contohnya dapat ditunjukkan dalam print screen di bawah ini. 


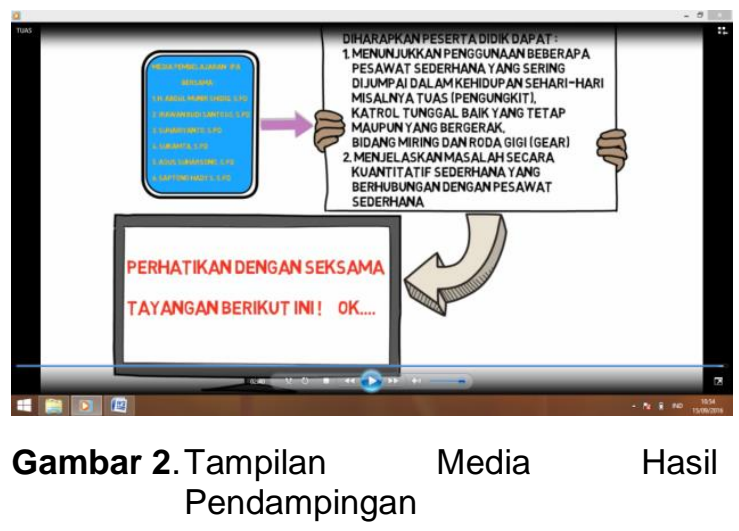

Teknik pembuatan media Flash-like PowerPoint, terdiri dari teknik timing, zooming, dan insertion.

Teknik timing adalah cara mengatur waktu tayang animasi yang dipilih pada PowerPoint. Jika di dalam satu slide terdapat lebih dari satu jenis animasi, maka seluruh animasi beserta urutan waktunya dapat dilihat pada tabulasi animation pane. Pengaturan dapat dilakukan dengan cara menggeser sinyal warna pada animation pane. Kalau ingin menyamakan waktu tayang animasi, seluruh sinyal warna ditempatkan menjadi satu garis lurus. Animation pane dapat diakses melalui menu animation $\rightarrow$ animation pane.

Teknik magnifikasi (zoom in), adalah teknik untuk mempresentasikan sebuah gambar. Pernah mempresentasikan sebuah gambar yang menampikan detil yang banyak, namun tidak terlalu jelas dilihat? Dengan teknik zooming in ini, bagian gambar yang hendak ditunjuk dapat diperbesar sehingga detil yang dimaksud dapat diamati dengan lebih jelas.

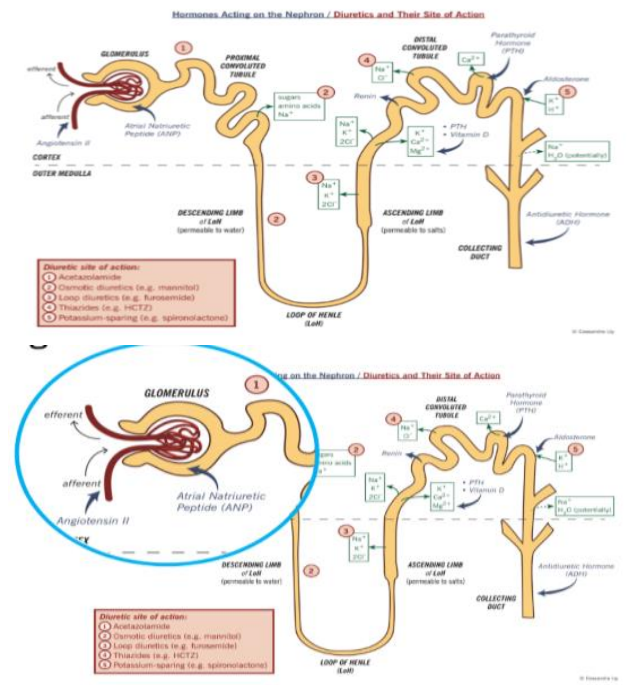

Gambar 3. Sebelum dan sesudah teknik zoom in diterapkan
Untuk melakukannya dapat dilakukan dengan cara memotong file (meng-crop) file gambar yang hendak diperjelas. Selanjutnya, gambar tersebut diberi garis tepi (border) dengan lingkaran dengan menggunakan shapes (insert $\rightarrow$ shapes). Selanjutnya, ukuran gambar disesuaikan dengan bagian gambar asli yang hendak diperbesar. Animasi yang ditambahkan pada gambar hasil crop ialah animasi zoom. Timing yang tertera di animation pane dibiarkan dengan pilihan defaultnya. Teknik zoom in sudah selesai dan siap dipraktikkan.

Teknik insertion ialah suatu teknik untuk menyisipkan. Hal-hal yang disipkan untuk bagian ini ialah soal quiz, ebook interaktif, dan video yang berekstensi flash. Untuk mempermudah melakukan teknik ini, software iSpring suiteversi 8 digunakan karena menyediakan fitur-fitur yang dimaksud. Berikut ialah screenshotnya.

Teknik hyperlink digunakan untuk memberikan link pada teks atau gambar sehingga apabila teks atau gambar tersebut diclick maka akan langsung menuju keterangan lebih lanjut yang dikehendaki. Untuk membuatnya, langkah yang paling mudah dilakukan ialah dengan cara menyorot teks atau gambar. Selanjutnya, opsi hyperlink akan muncul jika pada teks atau gambar dilakukan click kanan. Menu hyperlink yang telah dipilih akan menunjukkan kotak dialog pilihan tautan yang akan dikehendaki.

Flash-like PowerPoint yang telah dibuat dapat simpan dalam dua bentuk ekstensi yaitu.swf dan exe dengan cara mempublish dari ads-on iSpring suite 8.

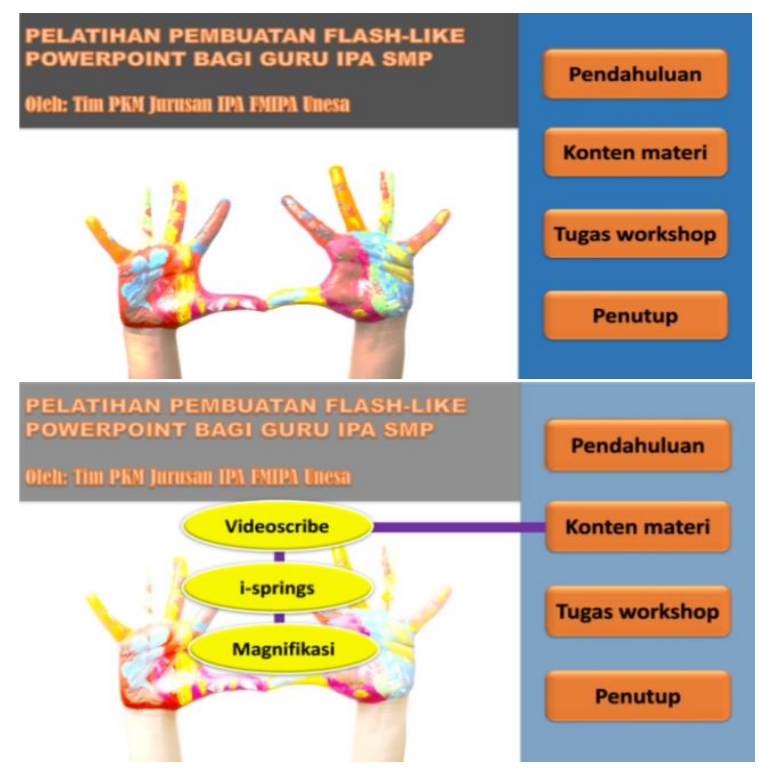

Gambar 4. Tampilan PPT-Flash-Like 
Media Flash-like PowerPoint yang dibuat oleh guru-guru dari sekolah mitra, diberikan penilaian meliputi beberapa kriteria sebagai berikut: organisasi, isi, grafis, dan animasi.

Hasil penilaian media Flash-like PowerPoint, ditunjukkan sebagai berikut.

Tabel 2. Hasil penilaian flash-like Power Point

\begin{tabular}{lcccc}
\hline \multirow{2}{*}{ Aspek } & \multicolumn{4}{c}{ Kelompok } \\
\cline { 2 - 5 } \multicolumn{1}{c}{ I } & II & III & IV \\
\hline Organisasi & 4 & 2 & 0 & 0 \\
Isi & 4 & 2 & 0 & 0 \\
Grafis & 4 & 3 & 0 & 0 \\
Animasi & 4 & 3 & 0 & 0 \\
Skor & 16 & 10 & 0 & 0 \\
\hline
\end{tabular}

Skor untuk kelompok I adalah tertinggi. Kelompok I dapat memperoleh nilai maksimal, karena anggota-anggotanya hampir dua pertiganya paham informasi teknologi, sehingga kelompok I sangat cepat dalam menyerap informasi yang diberikan oleh tim PKM. Untuk kelompok III, penilaian masih nol karena tim baru membuat dalam bentuk PPT, sedangkan untuk kelompok IV nilainya nol karena anggota tim yang bertugas membuat flash-like powerpoint, berhalangan hadir saat presentasi.

\section{Hambatan/Kendala dan Solusi}

Pendampingan pembuatan media flashlike PowerPoint, memerlukan perangkat komputer/laptop yang memadai, sehingga ketika sofware Scribe diinstalkan, tidak memerlukan waktu yang cukup lama untuk penginstalan. Selain itu, komputer/laptop yang memadai juga akan memudahkan/ memperlancar saat proses membuat medianya. Akan tetapi, pada beberapa peserta, laptop yang digunakan tidak mendukung untuk proses pembuatan media flash-like PowerPoint, sehingga mengalami keterlambatan saat peralihan dari satu sesi ke sesi berikutnya.

Solusi dari permasalahan di atas, tim PKM memberikan saran kepada beberapa peserta yang tertinggal, untuk bergabung dengan anggota tim lainnya. Selain itu, anggota tim PKM juga turun ke kelompok-kelompok untuk memberikan bantuan/bimbingan.

\section{Respon Peserta}

Pada akhir kegiatan pendampingan, tim pelaksana menjaring respon peserta terhadap kegiatan pendampingan dengan menggunakan instrumen respon. Hasil analisis data respon, ditunjukkan bahwa pada pernyataan yang bersifat positif (nomor: 1, 2, $3,5,6,7,8,11,12,13,16,17$, dan 19), respon peserta dominan pada setuju (S) dan sangat setuju (SS). Persentase peserta yang memberikan pernyataan setuju dan sangat setuju > $80 \%$. Ini menunjukkan bahwa peserta memberi respon positif terhadap kegiatan pendampingan yang diberikan. Demikian juga untuk pernyataan yang bersifat negatif (nomor 4, 9, 10,14,15, 18, dan 20), respon peserta dominan pada sangat tidak setuju (STS) dan tidak setuju (TS). Persentase peserta yang memberikan pernyataan sangat tidak setuju dan tidak setuju $>80 \%$. Ini juga menunjukkan bahwa peserta memberi respon positif terhadap kegiatan pendampingan, walaupun ada sebesar $5 \%$ (1 peserta) yang memberikan respon setuju untuk pernyataan negatif nomor 9 dan respon tidak setuju untuk pernyataan positif nomor 7 .

\section{SIMPULAN DAN SARAN}

Dari kegiatan pengabdian kepada masyarakat (PKM) ini, dapat disimpulkan bahwa kegiatan pendampingan pembuatan media flash-like PowerPoint direspon positif oleh peserta. Peserta merasa mendapat manfaat dari kegiatan ini. Peserta juga merasa lebih termotivasi untuk mengajar, dan utamanya peserta juga mendapatkan keterampilan (life skill) untuk mengembangkan media-media pembelajaran lebih lanjut.

Dari kegiatan pengabdian kepada masyarakat (PKM) ini, untuk materi $i$-Spring Suite belum ditindaklanjuti dengan workshop karena keterbatasan waktu, sehingga pada kegiatan PKM selanjutnya, materi tersebut bisa dilanjutkan dengan workshop agar guruguru IPA mempunyai keterampilan mengembangkan media pembelajaran dengan lebih maksimal.

\section{DAFTAR PUSTAKA}

Coleman, M. B. 2009. PowerPoint is not just for Business Presentations and College Lectures: Using PowerPoint to Enhance Instruction for Students with Disabilities. TEACHING Exceptional Children Plus. Vol. 6, Issue 1. 
Drouin, M., Hile R. E., Vartanian, L.R., dan Webb, J. 2013. Student Preferences for Online Lecture Formats: Does Prior Experience Matter?The Quarterly Review of Distance Education, Vol. 14(3), hal. 151-162 diakses melalui http://search.proquest.com/openview/ d371126d0c3894b1603756bbec1043 $8 \mathrm{~b} / 1$ ?pq-origsite $=$ gscholar

Harrington, R. dan Rekdal S. 2007. How to Wow with PowerPoint. Peachpit Press: Barkeley

Kozma, R. B. 1991. Learning with Media. Review of Educational Research. Vol. 61, hal. 179-212. Diakses melalui: https://www.google.co.id/url?sa=t\&rct $=\mathrm{j} \& \mathrm{q}=\&$ esrc $=\mathrm{s} \&$ source $=$ web\& $\mathrm{cd}=1 \& \mathrm{c}$ $\mathrm{ad}=\mathrm{rja} \&$ uact $=8 \& \mathrm{ved}=0 \mathrm{ahUKEwjT07W}$ W5_jLAhWSjo4KHTHRBI8QFggdMA A\&url=http\%3A\%2F\%2Frobertkozma. com\%2Fimages\%2Fkozma_rer.pdf\& usg=AFQjCNEjxuFSImltkJFtehazJUh 7vG62Zg

Departemen Pendidikan Nasional. 2006. Instrumen Penilaian Kinerga Guru IPKG 1. Depdiknas: Jakarta.

Departemen Pendidikan Nasional. 2006. Instrumen Penilaian Kinerga Guru IPKG 2. Depdiknas: Jakarta.

Direktorat Pembinaan Pendidikan Tenaga Kependidikan dan Ketenagaan Perguruan Tinggi. 2005. Peningkatan Kualitas Pembelajaran. P2TK: Jakarta 